\title{
NANO POWER DIPLOMACY Out of the Mainstream
}

\author{
Andrik Purwasito \\ Guru Besar Hubungan Internasional, FISIP-UNS, Surakarta, \\ Expert on Management of Inter-cultural Communication \\ email: andrikpurwasito@staff.uns.ac.id
}

\begin{abstract}
Abstrak
Nano power diplomacy adalah diplomasi yang dilakukan oleh individu dan kelompok kecil, tanpa tawar menawar dan negosiasi. Diplomasi tanpa teori dan pendekatan ilmiah, karena ia hanyalah noktah kecil-kecil (unit aktor) yang tidak membawa seperangkat real-power. Nano power diplomacy adalah kegiatan yang menekankan sharing of symbol antar warga, person to person direct contact. Artinya, nano power diplomacy adalah praktek diplomasi yang mendasarkan pada hubungan sosial-budaya antar warga, antar budaya, yang mencoba mengatasi berbagai perbedaan dan hambatan budaya dalam membangun satu komunitas manusia yang sederajat, seperti perbedaan ras, etnik, adat istiadat, bahasa, tingkat sosial-ekonomi, warna kulit dan perbedaan kepercayaan dan agama. Suatu diplomasi yang benar-benar diinisiasi oleh individu, yang tidak berbicara mengenai mediasi konflik dan perspektif ekonomis, tanpa tipologi bilateral, multilateral dan summit meeting, melainkan diplomasi yang menekankan komunikasi interaktif antar persona dan komunikasi publik. Tidak ada kerahasiaan, agenda tersembunyi dan hal-hal yang ditutupi (transparansi), karena setiap partisipan dalam nano power diplomacy adalah manusia yang dilahirkan oleh suatu produk takdir yang sama, yakni Tuhan Yang Maha Pencipta. Mereka berkembangbiak, makan dan minum dari jenis yang kurang lebih sama. Mereka juga mempunyai gaya hidup dengan cara yang kurang lebih sama. Terakhir, mereka juga berkomunikasi dengan cara dan pola yang kurang lebih sama, komunikasi verbal dan non-verbal. Jadi, manusia adalah makluk universal yang mempunyai kemampuan untuk hidup secara kekeluargaan. Di bawah ini dijelaskan mengenai asumsi dasar, metodologi dan pengertian nano power diplomacy

Kata Kunci : aktor, nano power diplomacy, antar-budaya, komunikasi, simbol, power.
\end{abstract}

\begin{abstract}
Nano power diplomacy is a diplomacy done by individuals and small groups, without bargaining and negotiating. Diplomacy without theoretical and scientific approaches, because it is just a small nod (actor unit) that does not carry a realpower set. Nano power diplomacy is an activity that emphasizes sharing of symbols between citizens, person to person direct contact. That is, nano power diplomacy is a diplomacy practice based on socio-cultural relations between people, between cultures, which tries to overcome differences and cultural barriers in building an equitable human community, such as race, ethnicity, customs, language, social level -economy, skin color and differences of trust and religion. A truly initiated diplomacy by the individual, which does not speak of conflict mediation and economic perspective, without bilateral, multilateral and summit meeting typologies, but diplomacy that emphasizes interpersonal communication and public communication. There is no secrecy, hidden agendas and transparencies, because
\end{abstract}


every participant in nano power diplomacy is a human being who is born by a product of the same destiny, namely God the Creator. They multiply, eat and drink of the same type. They also have a lifestyle in much the same way. Finally, they also communicate in more or less the same way and pattern, verbal and non-verbal communication. Thus, human beings are universal beings who have the ability to live in kinship. Below is described the basic assumptions, methodology and notions of nano power diplomacy

Keywords: actors, nano power diplomacy, intercultural, communication, symbols, power.

\section{A. Pendahuluan}

Diplomasi adalah seni berunding (The Oxford English Dictionary). Suatu penerapan keahlian dan taktik, manajemen dalam praktek hubungan internasional melalui negosiasi (Satow, 1917) yang diatur oleh state actor, yakni duta besar dan diplomat. Diplomasi juga dilakukan oleh non-state actor seperti pebisnis, seniman, mahasiswa, tokoh masyarakat, LSM, "diplomacy is the art of negotiation, especially of treaties between states. Diplomacy is also political skill (The Chamber's Twentieth Century Dictionary, dalam Purwasito, 2011: 212)

Ruang lingkup kegiatan diplomasi berada di luar batas yurisdiksi nasional yang diarahkan untuk mencapai berbagai kepentingan, seperti kepentingan keamanan nasional (Holsti, 1972: 145) yakni menjaga kedaulatan bangsa dan negara dari berbagai gangguan dan ancaman negara lain dengan melakukan

kerjasama militer dengan aktor negara lain, serta ikut aktif dalam menciptakan tata dunia yang aman, damai dan sejahtera. Selain itu, kepentingan ekonomi yang menjadi bagian penting dalam pencapaian kepentingan nasional di luar negeri dicapai melalui perundingan dan negosiasi. Maka dalam hal ini dibutuhkan keahlian politik agar meningkatkan ekspor, meningkatkan pertumbuhan ekonomi, perdagangan, investasi, pertukaran barang dan jasa.

Selanjutnya, kepentingan budaya, yakni suatu kegiatan diplomasi yang dilakukan melalui aktivitas seni, festival dan pameran produk Indonesia, selain ditujukan untuk memperat hubungan baik antara rakyat Indonesia dengan masyarakat dunia melalui kontak langsung, people to people contact, juga ditujukan untuk memperkokoh citra positif bangsa Indonesia di mata dunia. 
Oleh sebab kompleksitas kegiatan diplomasi dan pentingnya pemahaman yang lebih sistematis, Kautilya (Arthasastra, dalam Purwasito, 2011: 214) membagi diplomasi dalam empat yang saling menguntungkan. Pilar kedua, dikenal dengan preservation, yaitu suatu upaya untuk saling memelihara hubungan baik negaranegara agar memperoleh manfaat atas kerjasama internasional. Pilar ketiga adalah augmentation adalah tujuan yang diarahkan untuk meningkatkan

\section{B. Diplomasi Indonesia}

Diplomasi Indonesia paling mutakhir dapat kita lihat pada dua judul artikel dalam tabloid Kemenlu, yang diterbitkan oleh Direktorat Diplomasi Publik, (No. 101/X/01-02 2017). Kedua rubrik tersebut bagi saya memberikan gambaran yang jelas tentang diplomasi Indonesia kontemporer karena keduanya merupakan statemen dari orang yang paling berkompeten dalam urusan hubungan internasional, yaitu Presiden RI, Joko Widodo, yang menyatakan "Pentingnya Demokrasi bagi Kehidupan bernegara dan Hubungan Antar Negara." Kedua, adalah Menteri Luar Negeri RI, Retno Marsudi, dengan pernyataan "Di tengah Ketidakpastian Dunia, Diplomasi Indonesia terus Bekerja." pilar. Pilar pertama disebut sebagai acquisition, yakni suatu tujuan yang mengembangkan hubungan baik antar negara, dicapai melalui kerjasama

keuntungan di atas rata-rata. Pilar keempat, proper distribution, adalah tujuan diplomasi yang menjaga hubungan harmonis dan berkeadilan dalam berbagai aspek termasuk melindungi warga negara di negara asing (Roy, 1991: 1).

Dari dua judul di atas, saya memperoleh kesan, pertama, gambaran tentang demokrasi yang kita yakini sejak Proklamasi Kemerdekaan RI 1945 sampai hari ini, menyiratkan kesan bahwa kita masih mempertanyakan demokrasi sebagai landasan kehidupan bernegara dan hubungan internasional. Judul tersebut secara tersirat agaknya menandakan adanya gejolak dan dinamika politik yang menghendaki bukan demokrasi sebagai landasan. Saya yakin bahwa kalimat yang tersurat di atas adalah bukti penegasan Presiden sekaligus penguatan dan keyakinan bahwa tidak ada sistem negara yang paling baik kecuali demokrasi, termasuk dalam pelaksanaan diplomasi dalam hubungan internasional. 
Gambaran kedua adalah pernyataan dari Menlu, yang juga mengesankan adanya keraguan dalam melihat masa depan. Hal ini dapat dilihat dari kata standar yaitu "ketidakpastian dunia," yang sebenarnya memang masa depan tidak mungkin dipastikan. Pengambilan kalimat tersebut sungguh kurang berguna, mengingat sejarah telah membuktikan bahwa nyata benar masa depan tiada kepastian. Seharusnya kita mempunyai prediksi dan pilihanpilihan strategi, karena bagaimanapun masa depan hubungan internasional dapat diramalkan sejak kekinian. Itulah gunanya mengapa kita mempelajari ilmu HI dan mendirikan program studi HI di mana-mana.

Sejak awal berbicara tentang tatanan dunia global dan hubungan antar bangsa, kita melihat bahwa tatanan dan pola hubungan internasional tidak pernah bisa dijamin baik stabilitas maupun kondusifitasnya. Namun hubungan internasional dapat diprediksi. Kontinyuitas peradaban dan perjalanan kehidupan masyarakat global menunjukkan tanda-tanda yang tetap seperti kepanikan, keresahan, konflik dan anarkisnw.

Kalimat yang berbunyi "diplomasi Indonesia terus berjalan," menyiratkan bahwa pernyataan standar semacam itu kurang cerdas dan tidak menunjukkan strategi kualitas diplomasi kita. Ada kepastian ataupun tidak ada kepastian kondisi dunia, diplomasi Indonesia memang tidak pernah berhenti. Namun, kita mempunyai suatu strategi yang jelas. Agaknya saya memperoleh kesan bahwa idealisme dan pemahaman diplomasi bebas-aktif kita belum sepenuhnya mapan.Kekurang mapanan ini ditunjukkan melalui edar pendulum diplomasi kita yang liar. Ia bergoyang ke kanan dan ke kiri tanpa kendali, sehingga bergerak ke berbagai arah sepertinya hilang kendali.

Dengan kata lain, sisi konseptual ideal diplomasi bebas aktif kita mungkin sudah kokoh. Tetapi dalam prakteknya penulis melihat bahwa praktek diplomasi Indonesia belum mempunyai landasan falsafah yang kuat, suatu landasan yang selaras dengan dinamika dan spirit zaman. Sepertinya prakteknya politik luar negeri "bebas-aktif” sering diterjemahkan oleh penguasa secara arbitrair (sembarangan). Pendek kata, agar pendulum tidak bergerak liar, maka politik luar negeri "bebas-aktif," membutuhkan pernyataan yang tegas, seperti yang ditawarkan dalam paper 
ini yaitu diplomasi Pancasila, yakni bebas-aktif sesuai dengan sila-sila Pancasila.

Sejarah mencatat model atau lebih tepat disebut sebagai semboyan diplomasi Indonesia, misalnya Mohammad Hatta menyatakan diplomasi Indonesia "sailing between two rocks," (Hatta, 2015), Susilo Bambang Yudoyono, menyebut thousand friends, zero enemy, Joko Widodo, menyebut sebagai downearth diplomacy. Semboyansemboyan tersebut bukanlah menandai sifat dan karakter serta semangat zaman melainkan sekeder retorika dan semboyan diplomasi yang hanya permukaan. Bung Hatta mengatakan "kita tak mudah dengan begitu saja, dengan semboyan belaka..." (Hatta, 2015: 67). Maka diplomasi Indonesia harus menegaskan landasan dan semangat sejalan dengan pilar-pilar atau sila-sila Pancasila dan Undangundang dasar 1945, yang secara jelas menekankan pentingnya diplomasi berlandaskan religiositas, HAM, NKRI, demokrasi dan keadilan. Landasan tersebut membutuhkan penerjemahan secara praktis agar siapapun presidennya, politik luar negeri Indonesia berjalan sesuai jalurnya (on the track). Agar supaya kita mempunyai pendirian tetap agar politik luar negeri tidak dijalankan secara semena-mena, terombangambing di antara karang-karang yang ganas.

Paper di bawah ini mencoba menawarkan salah satu pilar dari diplomasi Pancasila, yang kami sebut dengan nano power diplomacy. Yakni diplomasi yang basis kekuatannya mendasarkan pada Ketuhanan YME, ber-azas kekeluargaan, kemanusiaan yang adil dan beradab, demokrasi, keadilan dan persatuan Indonesia. Prinsip diplomasi berlandaskan kekeluargaan tersebut sebagai hal sangat nyata, karena pada dasarnya “..... seluruh umat manusia memiliki hubungan langsung dengan Sang Pencipta tanpa memandang agama ataupun kekurangan mereka. Kita semua memiliki percikan ketuhanan di dalam diri kita. Saya memberikan penilaian kepada setiap orang dengan tanggapannya terhadap panggilan ketuhanannya, bukan berdasarkan etnisitas, agama ataupun rasnya." (Makow, 2015: 24).

\section{Diplomasi, Missing-Link dan Marginalisasi}

Beberapa ahli menyebutkan bahwa diplomasi adalah bidang studi 
yang sangat belum mapan (Carlsnaes, dkk, 2005: 436) bahkan kajian yang terabaikan dalam sejarah keilmuan HI, meskipun ia sebagai "soko guru" (Wright, 1978 dalam Jonsson dan Hall, 2005) atau Cohen menyebutnya sebagai "the engine room" (Cohen, 1998, ibid) dalam hubungan internasional. "Yet, diplomacy has received surprisingly little attention among political science specializing in international relations (ibid: 3). Akibat marginalisasi tersebut, kebutuhan referensi untuk kajian diplomasi sangat terbatas, terpisah dari perkembagan teori politik, yang mereka sebut sebagai "redundant and anecdotal." Akhirnya, kesenjangan antara studi teori HI dan praktek diplomasi tidak terjembatani secara baik, dan diperparah oleh kebanyakan para ahli yang mengkaji HI memfokuskan praktek diplomasi tetapi mengabaikan teori. Sedangkan mereka yang mengkaji teori HI namun kurang memfokuskan diri pada bidang diplomasi sebagai jantung hubungan internasional. (Jonsson dan Hall, ibid: 4)

Penjelasan di atas menunjukkan terjadinya "missing link," antara studi diplomasi sebagai praktek dalam hubungan internasional di satu pihak dan upaya kajian membangun teori diplomasi. Bahkan beberapa ahli mengatakan bahwa diplomasi sebagai seni praktek berunding dianggap kurang memenuhi standar ilmiah. Hal ini juga disebabkan kurangnya dukungan literature dan referensi bidang diplomasi yang memadai guna membangun teoritisasi diplomasi.

Pengalaman pada dua perang dunia menunjukkan peran diplomasi sangat penting dan terbukti sebagai lembaga yang tangguh menghadapi tantangan kedaulatan rakyat dan nasionalisme diabad ke 19 (Sharp, 1999 dalam Calrsnaes, dkk: 436) tetapi bidang tersebut masih belum tergali secara mendalam oleh beberapa sebab seperti adanya kerahasiaan dan redadensi (Jonsson dan Hall, ibid: 5).

Baru mulai tahun 1990an berdirinya lembaga kajian diplomasi dan jurnal serta serial publikasi tentang diplomasi, sebagaimana dilakukan oleh Institut Studi Diplomasi di Georgetown University, Pusat Studi Diplomasi di Universitas Leicester, Asosiasi Studi Internasional (ISA), Asosiasi Studi Internasional (BISA) di Inggris, serta lahirnya postmodernisme telah mendorong terjadinya debat teoritis. (Carlsnaes, dkk, op. cit.: 437). 
Pernyataan menarik dari Carlsnaes dkk, bahwa "perang sebagai lawan diplomasi" adalah pandangan dan gagasan yang khas Barat, yang belum tentu ditemukan dalam tradisitradisi di tempat lain (Cohen, dalam Carlsnaes, ibid: 438). Perkembangan sejarah menunjukkan bahwa istilah "diplomasi koersif" disebabkan oleh adanya fakta bahwa penggunaan power digunakan untuk mengancam dan membujuk dengan cara paksa agar pihak lain tidak melakukan intervensi atau mengubah statusquo yang ada.

Pernyataan Carlsnaes dkk tersebut merupakan salah satu alasan mengapa penulis mencoba mengangkat karya-karya khas Indonesia, yang penulis sebut sebagai bentuk "out of the mainstream" dalam kajian diplomasi dan hubungan internasional.

\section{Metodologi}

Definisi diplomasi yang bervariasi pada dasarnya mengacu pada perilaku aktor negara dan aktor non-negara. Metodologi yang mengacu pada paradigma struktural memfokuskan diri pada analisis struktur dan agensi. Diplomasi dikaji melalui praktek profesional dari para diplomat dan institusi serta organisasi dan admistrasi internasional. Sebagian ahli mengatakan bahwa memahami diplomasi dapat dilakukan melalui konsep-konsep generik seperti sistem representasi dan sistem komunikasi (ibid: 439). Jonsson dan Hall (The Essence of Diplomacy, 2005), dalam bukunya, yang mengkaji diplomasi dalam dua perspektif, yaitu diplomasi sebagai institusi (representasi), dan (2) diplomasi sebagai praktek negosiasi (komunikasi). Ia membangun teoritisasi melalui esensi diplomasi dengan tujuan agar teorinya mampu menjembatani antara teori dan praktek hubungan internasional. Artinya, agar terjadi ketersambungan logis (relevansi) antara studi hubungan internasional dengan diplomasi dan studi diplomai dengan hubungan internasional.

Sedangkan sebagian yang lain mengacu pada studi post-modernisme, yang mencoba keluar dari struktur dan agensi, memilih definisi diplomasi sebagai "mediasi antara individu dan kelompok atau entitas yang terasing." (Der Derian, 1978, ibid: 440). Dua kata penting yang menjadi fokus kajian dari definisi Der Derian yakni "keterasingan" dan "mediasi." Dua pihak yang terasing membutuhkan mediasi untuk melakukan pertemanan dan kerjasama. 
Untuk menguraikan nano diplomacy dalam upaya membangun teoritisasi diplomasi non-mainstream, untuk pertama kalinya kami menggunakan model analisis panggung wayang, yang kami sebut puppet shadow pargadigm. Yang dimaksud dengan non-mainstream adalah penggunaan sumber-sumber kajian dari locus setempat, digali dari berbagai khasanah, referensi sendiri, pengalaman dan habitus Indonesia. Untuk membangun analisis yang dialektik, sudah barang tentu kajian ini merupakan anti-tesa dari referensi diplomasi yang sudah ada.

\section{E. Kerangka Pikir}

Nano power diplomacy berawal dari kejengahan penulis melihat arena internasional yang selalu bergolak. Perdamaian internasional hanya sebuah nyanyian di tengah siang bolong, yang sewaktuwaktu bisa berubah menjadi nyanyian bom dan mitraliyur. Masyarakat yang makin beradab tidak menyurutkan dan meminimalisir kesalahpahaman, konflik regional, agresi militer, pertempuran senjata dan kekerasan. Sebaliknya disegala tempat terjadi kekerasan, peperangan, kelaparan, penindasan dengan berbagai bentuknya yang menyeramkan.
Penggalian awal sebagai antitesa dari pendekatan diplomasi kontemporer yang sudah dijelaskan di muka, setidaknya nano diplomacy kurang berkaitan langsung dengan empat faktor, yaitu: (1). Diplomasi di tengah tatanan internasional, (2). Diplomasi dalam situasi ancaman, prevelensi dan sifat perang yang berubah, (3). Diplomasi di tengah evolusi negara, (4). Diplomasi di tengah pengaruh kemajuan ilmu dan teknologi. (Hamilton dan Langhorne, 1993, Ibid: 444). Sebaliknya nano power diplomacy merupakan diplomasi yang berbasis individu dan kelompok kecil.

\section{Akhirnya,} peristiwa internasional seperti sebuah rekayasa beradab dari aktor intelektual yang tak menampak (anonimus). Setiap aktor internasional, SA dan NSA, tidak dapat melepaskan dirinya dari anonimus, sang hidden power, Sang Anonimus tidak kelihatan, tetapi gerakan mereka dalam upaya memperebutkan dan menguasai sumber-sumber ekonomi dunia sangat nyata. Seperti ketika kita menonton wayang di panggung belakang, kita hanya mendengar suara dan gerakangerakan, tetapi kita tidak tahu siapa yang menggerakkan aktor dan siapa 
yang bersuara itu. Sebuah dramaturgi yang sempurna.

Kolonialisme dan imperialisme adalah contoh awal perilaku menyimpang dari manusia atas manusia yang lain. Berawal dari mondialisme hubungan manusia sumber-sumber anarkhisme dan anonimus mulai lahir. Mereka seperti orang-orang yang keluar dari penjara maut, dengan mengatasnamakan penderitaan dan mungkin rasial, terus menegakkan supremasi dan identitasnya untuk melakukan balas dendam terhadap kekejaman sejarah yang telah menimpa mereka.

Dalam real-politik, panggung hubungan internasional dipresentasikan dalam situasi yang kacau balau dan carut marut. Posisi diplomasi sangat tidak menentu, mengingat diplomasi terkadang hanya kegiatan rahasia yang berada pada posisi persimpangan, meskipun ia "engine" dan "core" dari hubungan internasional, dalam prakteknya diplomasi hanyalah kegiatan mediasi, penyelesaian konflik, tawar menawar dan negosiasi.

Dari latar belakang itulah, penulis merasa perlu membangun seperangkat pengetahuan baru di luar pengertian dan praktek diplomasi yang selama ini diakui. Yaitu nano power diplomacy, yang berdampingan dengan soft power diplomacy, hard power diplomacy, dan smart power diplomacy. Nano power diplomacy adalah diplomasi yang dijalankan oleh kelompok kecil, yang saling menguntungkan tanpa resiko destruktif karena memang diplomasi ini berada di luar the game theory.

Hubungan internasional adalah bidang ilmu yang terus dikembangkan, bersifat lintas disiplin, lintasperadaban dan lintas sektoral. Bidang studi HI adalah bidang studi yang sangat kompleks dan sangat luas ruang lingkupnya. Bidang HI tidak hanya berbicara soal politik, ekonomi dan militer, tetapi mencakup seluruh kegiatan kehidupan manusia. Suatu bidang studi yang membicarakan interaksi dan komunikasi kemanusiaan yang tak terbatas ras dan agama. Dalam konsep nano power diplomacy, hubungan internasional dipandang sebagai arena hidup berkeluarga.

Kompleksitas dan keluasan ruang lingkup tersebut, studi HI mencirikan dirinya sebagai disiplin ilmu yang secara metodologis transdisiplin, multidisiplin, dan interdisipliner. Secara struktural disiplin HI bersifat hierarkhis, heterogen, dan eklektif (Carlsnaes, dkk, op.cit.: 707). Secara historis, 
ruang dan waktu, hubungan internasional bersifat dinamik dan kompleks. Secara praktek bersifat damai dan anarkhis. Maka tidak mengherankan jika secara konseptual disiplin keilmuan $\mathrm{HI}$ masih rancu secara konseptual, kaburnya kepercayaan sebagai bidang yang mandiri, tumpang tindihnya teori, terutama dalam tinjauan antara etika, estetika, idealisme dengan realitas, anarkhisme, liberalisme, dll.

Maka, pemikiran HI yang realism sebagaimana dikerjakan secara baik oleh Hans J. Morgenthau (Morgenthau, 1967) selalu relevan, bahwa disiplin HI fokus dominannya terletak pada perjuangan setiap aktor dalam memenuhi kebutuhan dan kepentingan nasionalnya. Hubungan internasional adalah perjuangan setiap aktor untuk mendapatkan kekuasaan (struggle for power). Unsur kekuasan nasional (national power) harus menjadi realitas yang perlu dipenuhi agar menjadi sangat besar, agar mampu menguasai power optimum sehingga mampu mengendalikan dunia. Besar kecilnya national power mempengaruhi konstelasi politik dan pencapaian ekonomi serta bargaining power di panggung internasional. Konsep tersebut melanjutkan formula Karl Marx tentang masyarakat yang terbagi ke dalam kelas-kelas. Setiap setiap orang atau kelompok yang tergabung dalam kelas selalu berjuang untuk kelasnya (struggle for class).

Kesimpulannya, bahwa dalam kehidupan lokal, nasional atau kehidupan internasional, juga terbagi dalam kelas-kelas yang hierarkhis, yang mana satu kelas secara alamiah menindas (hegemoni) atas kelas yang lain, dalam khasanah Prancis disebut l'exploitation de l'homme par l'homme. Dengan kata lain, kelaskelas yang hierarkis menandakan terjadinya unequality (ketaksederajatan), rentan terhadap penindasan, ketidakberdayaan, dominasi, hegemoni dan ketidakadilan. Begitu juga dalam panggung hubungan internasional, arena yang global dan mondial tersebut rapuh terhadap konsep persaudaraan hanya karena perbedaan. Ibarat hidup di hutan rimba belantara, dalam kehidupan internasional, juga berlaku hukum rimba, yang kuat yang menang, seperti adagimum politik, tidak ada kawan yang abadi kecuali hanya kepentingan (Purwasito, 2011: 16).

Berlakunya hukum rimba telah menjelaskan secara jelas bahwa hubungan internasional berlaku formula "mereka yang kuat mereka 
yang menang." Kondisi yang hierarkhis dalam hubungan internasional tersebut mengakibatkan hubungan antar negara dan antar orang menjadi hubungan antara yang superior dan yang inferior, yang rentan melahirkan ketidakharmonisan, pincang dan dominatif. Dalam sistem pendidikan global terdapat sistem rangking dan standar kelas-kelas yang diikuti oleh ribuan perguruan tinggi yang berjuang demi rangking dan kelas-kelas. Di belakang standarisasi tersebut adalah sebuah arena atau panggung kapitalisme, yaitu pasar.

Situasi dan kondisi yang demikian itu, mengharuskan studi HI melahirkan teori-teori internasional yang berbasis opposite binaire yakni (1) pihak yang kuat (super power) berhadapan dengan pihak yang lemah (less power), (2) pihak yang dipusaran terdalam (centrum) dengan pihak yang berada di luar pusaran (out of cycle), (3) pihak yang berada di pusat (core) dan pihak yang ada di pinggiran (periphery),, (4) pihak yang bersekutu (in-group) dengan pihak yang tercerai berai (out-group), (5) pihak yang aktif dengan pihak yang pasif, (6). Pihak yang bermain (role-play) dengan pihak yang teraleniasi (audience), (7) pihak yang berkembang (developing countries) menang dan hegemonis dengan pihak yang gagal dan krisis (under developing).

Dalam fakta obyektif tersebut, kita menyadari bahwa ada aktor sentral (dalang) yang mengatur dan menggerakkan perubahan serta mendinamisir dinamika internasional. Aktor sentral, yang kami sebut anonimus, (Purwasito, Anonimus: 2017) menjalankan perannya secara tak kasat mata, tetapi mereka mempunyai kemampuan menggerakkan aktor SA dan NSA yang bermain di layar depan. Sedangkan hasil dari perjuangan power oleh para aktor tersebut didistribusikan sesuai dengan kesepakatan. Aktor internasional di layar depan bisa jadi SA (state actor) yaitu aktor negara, bisa juga NSA (non-state actors) yaitu aktor nonnegara, seperti IGO, NGO, MNC yang pada prinsipnya memenuhi ambisi untuk menjamin dan melindungi kepentingan anggotanya, “......assurer la protection des interest de leurs members... (Merle, 1998: 397). Dalam model puppetshadow paradigm aktor-aktor internasional tersebut tidak ubahnya wayang, yang berperilaku sesuai dengan grand scenario yang dibuat oleh sang dalang anonimus, “....d'un 
pouvoir anonyme, rival des Etats...." (Merle, 1998, op.cit.: 407).

Pada akhirnya pelaksanaan hubungan internasional adalah arena bagi-bagi hasil, yang mana oara aktor negara melakukan pembagian keuntungan ekonomis dan politis dengan anonimus, melalui summit meeting. Hasil tawar menawar, transaksi dan negosiasi tersebut tidak diformulasikan dalam kebijakan politik luar negeri aktor negara, karena pada hakekatnya kebijakan luar negeri bersifat idealis dengan suatu doktrin upaya mencapai kepentingan nasional sebesar-besarnya. Perangkat-perangkat untuk mencapai kepentingan nasional di luar negeri tersebut dibuat secara idealistik oleh Kementerian Luar Negeri, Ministry of International affairs, tanpa perhitungan matematis dari hasil pencapaian yang dilakukan oleh para agen-agennya.

Dalam prakteknya, yang disebut pencapaian kepentingan nasional yang optimum dan yang dibangga-banggakan tersebut sesungguhnya hanyalah dokumen imajinatif (teks klangenan). Hal ini disebabkan oleh konsep normatif yang sangat tinggi dikalahkan kenyataan oleh nafsu serakah anonimus dan anarkhisme internasional. Artinya bahwa keuntungan-keuntungan dari diplomasi para aktor jika dihitung secara matematis tidak sebanding dengan pemilikan asset, kerja keras dan jumlah penduduk. Pembagian dan perhitungan keuntungan yang tidak seimbang, menunjukkan langkah diplomasi mengalami kegagalan. Contoh kecil misalnya pembebasan sandera Indonesia oleh para pembajak di lautan, baik oleh pembajak Somalia maupun pembajak Abu Sayaf di Filipina, uang tebusan menjadi faktor menentukan. Sepertinya diplomasi tidak berhasil karena rendahnya posisi tawar menawar dan lemahnya faktor negosiator. Contoh lain yang cukup signifikan adalah pembagian keuntungan antara Pemerintah RI dan Freeport di Papua.

Selama pembagian keuntungan antara negara dengan pihak lain bersifat adil, maka hal itu tidak menjadi masalah. Namun, kenyataan menunjukkan bahwa keuntungan yang diberikan kepada pihak lain oleh aktor internasional tetap lebih besar dibandingkan dengan penerimaan keuntungan yang diterima untuk rakyat mereka. Seperti halnya ikatan hutang luar negeri, yang harusnya mampu untuk menyejahterakan rakyat, justru digunakan untuk membayar bunga. Rakyat kebanyakan hanya menerima nikmat sebagian 
kecil saja dan tidak sedikit rakyat menunai kesedihan dan mandi air mata.

Bagi SA (aktor non-negara), yang menjalankan delapan track diplomasi, sebagian dari mereka beroirentasi pada kepentingan negara, sebagian yang lain tidak mempunyai orientasi pada kepentingan nasional negara, kecuali untuk kesejahteraan anggotanya. Hadirnya kantor internasional, layanan internasional, urusan internasional, hadirnya kelompok dan invidu yang bekerja secara internasional untuk bidangbidang tertentu, seperti kegiatan budaya, turisme, pendidikan, menandakan diplomasi aktor nonnegara dapat terlaksana dengan baik. Bagi kelompok ekonomi berskala global seperti Multi-national Corporation (MNC) yang membangun oligopolies di seluruh dunia, dalam operasi globalnya, di layar belakang tetap melakukan transaksi dan negosiasi dengan anonimus, tidak peduli dengan cara-cara mereka yang anarkhis (Merle, 1988, op. cit.: 399).

Untuk itulah, Indonesia sebagai negara hukum dan negara peradaban (Mohammad Hatta, 1981) perlu mempunyai landasan falsafati yang kuat. Di tengah panggung internasional yang kompleks dan tidak menentu, yang mana kisah peradaban manusia tidak hanya terancam dan diombang-ambingkan oleh nafsu kebinatangan, melainkan peradaban yang sudah memasuki masa penghancuran global. Norma dan nilai manusia yang adiluhung telah dibolakbalik, penghargaan hak-hak manusia diabaikan, fakta obyektif dan kebenaran dijungkir-balikan, cita-cita kehidupan yang sakinah, mawadah, warohmah telah diteror melalui ideologi-ideologi baru dengan moralitas baru seperti holliganisme, hedonisme, LBGT dan penyelewengan terhadap gagasan gender. Sejarah dan agama direkayasa sesuai dengan kepentingan dirinya sendiri, etnik, rasialisme, apartheid dipertentangkan secara tajam.

Dengan kata lain, bahwa mereka yang adi-kuasalah (power) yang besar kemungkinan mempunyai peluang untuk menjadi dalang. Di belakang mereka adalah anonimus yang mempunyai kesanggupan yang luar biasa untuk memaksakan kehendaknya secara massif, termasuk menentukan standar moral, menentukan bentuk keadilan, menciptakan rasa aman dan menebar kekerasan dan kekacauan di manamana. Amerika Serikat, seperti yang dikatakan oleh Hillary Clinton dalam 
pidatonya (Youtube: 2017) bahwa politik luar negeri AS mutakhir bersifat pragmatis dan bukan bersifat ideologis yang kaku. Artinya, kepentingan material ekonomi, politik, ekonomi dan militer lebih diutamakan ketimbang keuntungan ideologi. Hal itu dapat dimengerti ketika AS telah berhasil menjalankan diplomasi ideologi sejak setelah Perang Dunia Pertama, yakni dengan promosi demokratisasi dunia. Sejarah mencatat bahwa gerakan demokratisasi telah berhasil mengubah tatanan sosial dunia sehingga demokrasi telah menjadi pendulum penggerak negaranegara untuk saling berdekatan, bekerjasama dan menjalin persahabatan untuk mewujudkan kehidupan yang damai. Untuk itulah AS cenderung menentukan standar politik luar negerinya dengan smart power diplomacy.

Sementara itu, dukungan dan kontribusi media massa global, yang kepemilikannya dikuasai oleh milliarder, pada hakekatnya adalah sebagi alat dan sarana (channel) soft power imperialism untuk mempromosikan sekaligus memprogandakan kehidupan baru yang beorientasi pada kehidupan profan, misalnya menerima gagasan moralitas dan nilai-nilai baru kehidupan lesbian, biseks, gay, dan transgender (LBGT), termasuk propaganda besar-besaran terhadap gerakan anti-terrorisme dan antifundamentalisme sebagai musuh kemanusiaan. Pada hal di panggung belakang mereka itu dikendalikan oleh anonimus yang mempunyai agenda tersembunyi, yakni agenda penguasaan dunia melalui pendudukan wilayah-wilayah potensial secara ekonomi dan strategi.

Hasilnya, diplomasi yang bertugas untuk perdamaian dunia, tetapi dalam praktek, diplomasi dijadikan sarana melanggengkan hegemoni negara Adikuasa. Nyatanya diplomasi terus dijalankan tetapi perang terus dilangsungkan. Akhirnya mempelajar diplomasi tampak menjadi suatu bidang yang sia-sia. Sistem internasional menjadi anarkhis, setiap aktor selalu mengendepankan pertimbangan pragmatis yang dijalankan secara semena-mena dengan metoda menghalalkan segala cara (Machiavelli, 2008).

Dalam siatuasi dan kondisi hubungan internasional tersebut di atas, kami pandang perlu untuk menghadirkan Nano power diplomacy, yang memungkinkan sebagai alternatif konsep diplomasi baru untuk memenangkan perjuangan diplomasi. 
Bagi bangsa Indonesia nano power diplomacy selaras dengan kepemilikan national power dan keunggulan daya saing bangsa di panggung internasional.

\section{F. Nano Power Diplomacy}

Dari penjelasan di atas, kita memperoleh kesimpulan bahwa nano power diplomacy mempunyai landasan yang kuat sebagai konsep diplomasi yang baru. Pertama, sebagai anti-tesa terhadap hubungan internasional yang anarkhis menjadi hubungan kekeluargaan, fammiliarity. Hal ini menegaskan pentingnya menerjemahkan konsep diplomasi

Dengan kata lain, nano power diplomascy adalah jenis diplomasi yang bercorak micro atau retail diplomacy yang dijalankan oleh netizen (secara individu atau kelompok kecil), di satu pihak kepada individu, kelompok atau publik di negara lain. Pelaku, netizen atau aktor retail tersebut mempunyai misi mempromosikan potensi negara dan produk budaya bangsa Indonesia secara sukarela dan tidak mengambil keuntungan finanasial (non-profit diplomacy). Di pihak lain, netizen, sesuai dengan takdirnya, menjalankan diplomasi retail tersebut melalui aktivitas-aktivitas di dunia maya (cyberspace). Baik melalui media sebagai netizen to netizen contact. Kedua, upaya untuk mengangkat setiap orang menjadi diplomat, every body is diplomat. Ketiga, praktek diplomasi dijalankan dalam skala yang kecil, yakni bersifat personal dan kelompok kecil (small group). Jika digambarkan sebagai berikut :

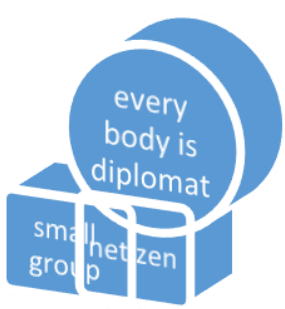

Gambar : Unsur-unsur penting dalam nano power diplomacy. sosial maupun media bloggers. Kelahiran komunitas bloggers ASEAN, yang mana penulis ikut serta menginisiasi lahirnya komunitas tersebut 2013 di Balai Diklat Kemenlu Jakarta.

Perhelatan angklung oleh KBRI, di Beijing Worker's Gymasium, Cina, 30 Juni 2013, dimainkan oleh penduduk lokal Beijing kurang lebih 5393 orang berhasil menembus rekor "Guinness World Records," (Wartapedia.com, 1/07/2013) yang sebelumnya dipegang oleh KBRI Washington DC yang diadakan di National Mall 9 Juli 2011 (Kompas.com, 23 April 2011). 
Penggunaan teknik dan praktek diplomasi di luar struktur formal, diplomasi tidak resmi, oleh personalpersonal yang tidak terikat oleh struktur, bersifat informal, dalam beberapa hal difasilitasi oleh pemerintah, justru lebih efektif menjalankan fungsi diplomasi sipil yang sederhana. Konsep diplomasi tersebut memperkuat posisi multitrack diplomacy, (Diamond, McDonald, 1996:1-2), khususnya track kedua, yakni keikutsertaan sipil dalam ikut aktif membangun perdamaian dunia (Joseph Montville, 1991: dalam Thompson and Jensen).

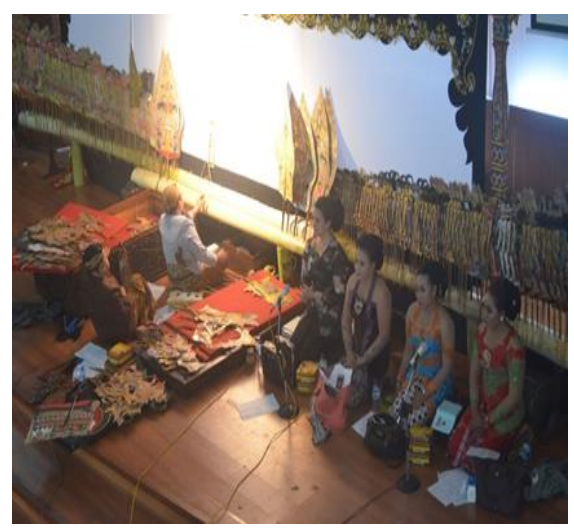

Pagelaran panggung wayang Andrik Purwasito, sebagai praktek nano power diplomacy.

Di program studi Hubungan Internasional, FISIP, UNS, penulis mengembangkan nano diplomacy dalam bidang (1). Promosi heritage; (2). kuliner; (3). batik dan Handycraft; (4). seni Pertunjukan, khususnya wayang; (5). aktivitas cyberspace, upload hasil karya mahasiswa untuk dua kuliah "praktek diplomasi" dan mata kuliah "komunikasi internasional dan diplomasi publik." Dua mata kuliah tersebut juga ikut menginspirasi lahirnya nano power diplomacy, suatu bentuk netizen to netizen contact.. Karya-karya tersebut dapat di akses di youtube.com

Selain pengalaman di kelas, penulis juga mempunyai pengalaman dan praktek retail diplomasi di beberapa negara, seperti Bulgaria, Moldova, Romania (2015), Rusia (2016), Jepang (2016-2017), India (2017), melalui workshop dan pagelaran serta pengajaran, wayang, heritage, batik dan kuliner. Pengalaman dan praktek langsung tersebut menginspirasi penulis untuk menegaskan bahwa nano power diplomacy sangat efektif dalam mendekatkan budaya Indonesia dengan budaya bangsa asing melalui person to person contact.

\section{G. Kesimpulan}

Dari apa yang diuraikan di atas dapat disimpulkan bahwa diplomasi dalam skala mikro atau retail dapat dijalankan oleh netizen, baik secara langsung hadir di negara asing maupun berdiplomasi melalui saluran on-line di cyberspace. Pelaku tidak harus bergantung pada saluran resmi, dilakukan secara informal, dan tidak bergantung pula pada pembiayaan dan 
jadual pemerintah. Namun demikian, alangkah baiknya apabila nano diplomasi melibatkan stakeholders, terutama Kemenlu, Kemendikbud, Kementeriaan Pariwisata, dll. agar efektivitas diplomasi semakin lebih kuat dan nyata.

Sifat dari diplomasi nano adalah non-profit dan dilakukan secara suka rela, mendasarkan pada asas kekeluargaan sebagai warga manusia yang mempunyai kesamaan universal. Apabila setiap netizen mempunyai kesadaran membangun diplomasi secara massif maka dapat dipastikan terjadinya gemerlapan sinar bintangbintang kecil di langit global. Dengan penjelasan tersebut, nano power diplomacy mendefinisikan setiap orang adalah diplomat (everybody is diplomat). Demikian tulisan ini semoga bermanfaat. (Prodi HI-FISIPUNS, 2017)

\section{DAFTAR PUSTAKA}

Buku:

Carlsnaes, Walter, Thomas Risse, Beth A Simmons. (2013), Hand Book Hubungan Internasional, versi Indonesia, Bandung, Nusa Media

Diamond, Louse, McDonald, John (1996), Multi-Track
Diplomacy: $\quad$ A System Approach to Peace, Connecticut: Kumarian Press Hatta, Mohammad (1981), Kumpulan Pidato, Jakarta: Penerbit Yayasan Idayu

(2015),

Mendayung Antara Dua Karang, Bandung : Penerbit Sega Arsy

Holsti, K.J. (1972). International Politics: A Framework for Analysis, $2^{\text {nd }}$ edn, Englewood Cliffs: Prentice Hall

Machiavelli, Niccolo, Il Principle,

Sang Pangeran, versi Indonesia, Yogyakarta: Penerbit PT Narasi

Makow, Henry, Illuminati, Dunia dalam Genggaman Perkumpulan Setan, versi Indonesia, Jakarta: Penerbit Ufuk Publishing House.

Merle, Marcel, (1988), Sociologie des Relations Internationales, Paris: Dalloz

Montville, Yoseph. V, (1991), "Transnationalism and the Role of Track Two Diplomacy," dalam Thompson W. Scott, dan Jensen, Kenneth M, ed, Approaches to Pease: An intellectual Map. Washinton 
DC: States Institute of Peace

Press.

Morgenthau, Hans, J. (1967), Politics

Among Nations: The

Struggle for Power and

Peace, $4^{\text {th }}$ edn, New York,

Alfred Knopf.

Purwasito, Andrik (2015), Komunikasi

Multikultural, Yogyakarta:

Penerbit Pustaka Pelajar

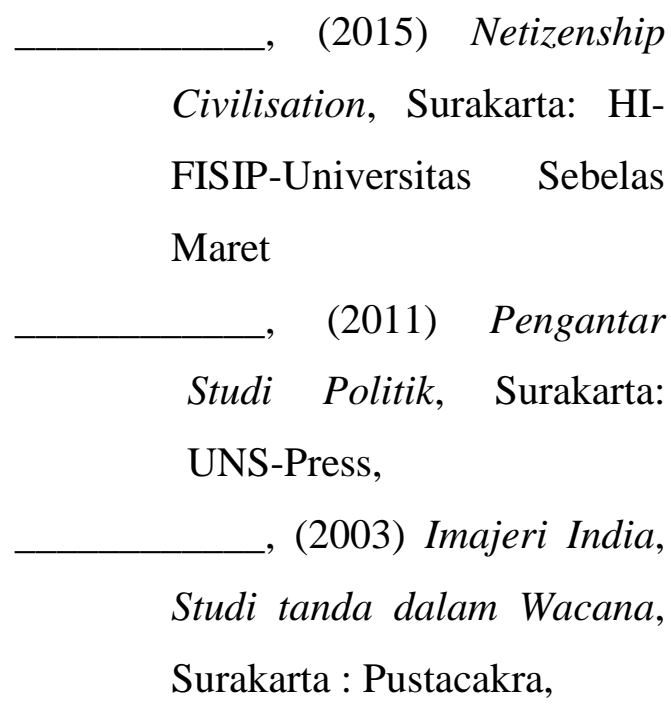

Roy, S.L.(1991). Diplomasi, edisi versi

Indonesia, Jakarta: Rajawali

Pers

Satow, Ernest. (1917), Guide to

Diplomatic Practice. London and New York, Longmans, Green \& Co, dalam Carlsnaes (2013).

\section{Dictionary:}

The Oxford English Dictionary

The Chamber's Twentieth Century

Dictionary

\section{Internet:}

http://travel.kompas.com/read/2011/04 /23/09325875/RI-bertekadrebut-rekor- dunia-angklung http://wartapedia.com/dunia/ dunia/11881-kbri-beijingpertunjukan-angklung-oleh5393-orang-pecahkan-rekordunia

\section{Youtube:}

Youtube. (download June, 2017) Hillary Clinton Advocates : Smart Power 